\title{
Inventário da arborização urbana das principais avenidas do Município de Rorainópolis, Roraima
}

\author{
José Neto Veloso \\ Universidade Estadual de Roraima (UERR). Curso de Engenharia Florestal. Campus Rorainópolis, Av. Senador Hélio \\ Campos s.n, CEP 69373-000, Rorainópolis, Roraima \\ Email: netinhoveloso@hotmail.com
}

Recebido em: 12 de setembro de 2016. Aceito em: 25 de outubro de 2016. Publicado PDF em: 01 de novembro de 2016

\section{RESUMO}

Inventário da arborização urbana das principais avenidas do município de Rorainópolis, Roraima. A arborização urbana proporciona inúmeros benefícios à população de uma cidade, dentre eles podemos destacar os ambientais e sociais. Porém, se não for feito um correto planejamento na hora de implantar a arborização de uma cidade, vários transtornos poderão ocorrer. $\mathrm{O}$ objetivo deste estudo foi avaliar de forma qualitativa e quantitativa a arborização das principais Avenidas do Município de Rorainópolis, Roraima. Para tanto, foi adotado o método de inventário censo, ou seja, foram inventariados todos os indivíduos arbóreos e arbustivos de cinco Avenidas. Foi amostrada uma população de 442 indivíduos, sendo que 213 são plantas arbustivas, distribuídas em 05 espécies e 04 famílias, sendo Ixora coccinea a espécie mais frequente e 229 plantas arbóreas distribuídas em 16 espécies e 12 famílias, sendo Ficus benjamina a espécie que ocorreu com maior frequência. Foram encontrados vários problemas nas vias estudadas, entre eles podemos destacar o uso de cal no tronco de árvores, espécies infestadas por erva-de-passarinho e galhos de árvores com risco de queda. A maioria das espécies das avenidas são exóticas (62\%). 52,26\% dos indivíduos foram avaliados na condição de ótimo, ou seja, eram indivíduos vigorosos e sadios. $23,02 \%$ dos indivíduos possuíam suas copas normais, ou seja, não foram submetidas a nem um tipo de poda e $99 \%$ das espécies estudadas não apresentaram danos às calçadas. Há uma necessidade de um melhor planejamento na arborização das Avenidas desta cidade e também é necessária uma substituição de espécies, bem como uma melhor manutenção das espécies inseridas nesses espaços.

PALAVRAS CHAVE: Arborização de vias públicas, Planejamento urbano, qualidade ambiental.

\section{ABSTRACT}

Inventory of urban forestation in main avenues of Rorainópolis, Roraima state. The urban forestation provides numerous benefits to the town's population; among of these we can emphasize the environmental and social benefits. However, if it is not done a correct planning with respect to the hour to implant the forestation of any town, various disorders will happen inside the urban area. This work aims to measure on qualitative and quantitative form the forestation on the main avenues in Rorainópolis town, Roraima. The inventory census method was adopted, that is, every individual tree and bush of five avenues was inventoried. A population of 442 individual plants was showed; out of them 213 are bush trees distributed in 05 species and 04 families, and Ixora coccinea was the more frequently bush specie occurred and 229 tree plants distributed in 16 species and 12 families, and Ficus benjamina was the more frequently specie occurred. Various problems were founded on the studied avenues, among of them we can emphasize the use of lime on trunk trees, species infested with mistletoe and branches with falling down risk. The majority of species on the avenues are exotics (62\%). Out of them 52,26\% individual plant was availed like good condition, that is, they were vigorous and healthy. $23,02 \%$ of each plant was found with normal top, that is, they were not submitted to any kind of pruning; and $99 \%$ of the studied species did not content damage to the sidewalk. A better forestation planning on this town's avenues and species replacing are required and a better species maintenance that exist on these areas.

KEY WORDS: Public streets forestation, urban planning, environmental quality. 


\section{INTRODUÇÃO}

Arborização urbana é o conjunto de terras públicas e privadas, com espécies predominantemente arbóreas que uma cidade apresenta, ou ainda, é um conjunto de vegetação arbórea natural ou cultivada que uma cidade apresenta em áreas particulares, praças, parques e vias públicas (Silva Júnior \& Mônico 1994).

Conforme Silva et al. (2008), as árvores urbanas trazem muitos benefícios para os habitantes das cidades: reduzem o calor e a poluição atmosférica e sonora; diminuem a velocidade dos ventos; produzem sombra; captam e drenam água evitando enchentes, contribuem para a formação das nuvens; embelezam ruas, canteiros, praças e jardins; protegem o solo; e atraem a avifauna, dentre outros benefícios. Por esta razão, atualmente, tem sido mais valorizada à prática da arborização urbana.

Cada cidade tem clima próprio e tipo de solo característico, o que torna necessário a escolha de espécies arbóreas adequadas a essas condições para que possam promover seus potenciais benefícios (Silva 2012). Além disso, estas plantas necessitam de cuidados e reparos periódicos evitando a introdução e proliferação de agentes fitopagênicos, a prática de ações prejudiciais como, por exemplo, podas inadequadas, conflitos com equipamentos urbanos e impactos mecânicos.

A presença da vegetação nos canteiros centrais de avenidas também exerce influência positiva no bem estar dos transeuntes, assim como confere um caráter plástico a paisagem (Andreatta et al. 2011).

Em cidades tropicais de clima quente como é o caso do Município de RorainópolisRR, faz-se necessário o uso da arborização urbana nas vias públicas para que a mesma possa contribuir com as condições ecológicas e edafo-climáticas do Município.

Portanto, diante desse quadro, o estudo teve como objetivo principal caracterizar a arborização urbana por meio de um inventário qualitativo e quantitativo das espécies arbóreas e arbustivas nas principais avenidas do município de Rorainópolis. Para esse intento foram delineados quatro objetivos específicos: 1. Catalogar as espécies arbóreas e arbustivas, bem como suas origens; 2. Determinar o estado geral dos indivíduos quanto à fitossanidade; 3 . Determinar a integridade da copa das árvores de cinco Avenidas; 4. Diagnosticar o desenvolvimento do sistema radicular das espécies vegetais em relação à calçada.

\section{MATERIAL E MÉTODOS}

Área de estudo: Segundo o Ministério de Desenvolvimento Agrário (2010), o Município de Rorainópolis nasceu com denominação de Vila do INCRA, numa referência ao Projeto de Assentamento Dirigido Anauá PAD/ANAUA, que possui sua sede nesta localidade, desde 1975, para instalação dos colonos migrantes de outros Estados do Brasil. O mesmo foi transformado em Município pela Lei $\mathrm{n}^{\mathrm{o}} 100$ de 17 de outubro de 1995, com terras desmembradas do Município de São Luís do Anauá.

O município de Rorainópolis está localizado ao sul do Estado de Roraima, (Figura 1A) na mesorregião Sul, microrregião Sudeste, situado nas coordenadas geográficas $60^{\circ} 25^{\prime} 47^{\prime}$ " W e $00^{\circ} 56^{\prime} 46^{\prime \prime} \mathrm{N}$ (SEPLAN 2009). $\mathrm{O}$ município possui uma área territorial de $33.595,892 \mathrm{~km} 2$ que corresponde a $14,98 \%$ do território de Roraima (SEPLAN 2010). Rorainópolis está localizado $291 \mathrm{~km}$ da capital Boa Vista, as margens da rodovia federal interamericana BR 174, que interliga Santa Helena do Uairen (fronteira entre Brasil e Venezuela) com o Estado do Amazonas (MDA, 2010). Cabe ressaltar que Rorainópolis é formado por cinco distritos: Martins Pereira, Nova Colina, Equador, Jundiá e Santa Maria do Boiaçu. $O$ trabalho foi realizado na sede municipal de Rorainópolis-RR.

Segundo o Instituto Brasileiro de Geografia e Estatísticas - IBGE (2015) a população estimada para o Município de Rorainópolis é de aproximadamente 27.288 habitantes.

Segundo o Ministério da Defesa (2004), em Rorainópolis o clima é predominante quente, com chuvas de verão e outono (AW'I), com temperatura média anual de $26^{\circ} \mathrm{C}$ e a precipitação pluviométrica é de $1.750 \mathrm{~mm}$, apresenta uma cobertura vegetal caracterizada por Floresta Ombrófila Densa e área de contato (formação pioneira / floresta), além de apresentar uma grande diversidade de solos.

Segundo o Ministério da Defesa (2004), Rorainópolis apresenta uma grande variedade de tipos de solos como Podzol Hidromorfíco, Areia Quartzosa Hidromorfica, Podzólico Vermelho-Amarelo, Latossolo Vermelho- 
Amarelo, Areia Quartzosa, Solo Hidromórfico Gleyzados e Latossolo Amarelo.

Foram estudadas cinco avenidas, sendo que estas são denominadas: Avenida Doutora Yandara, Avenida Senador Hélio Campos, Avenida Ayrton Sena, Avenida Tancredo Neves e Avenida Brigadeiro Ottomar de Sousa Pinto (Figura 1B).

Metodologia: A identificação das espécies encontradas ocorreu por meio da consulta bibliográfica conforme descrito por Lorenzi et al. (1998, 2000, 2001, 2004). Em sites especializados, como o trópicos.org., além do auxílio de um profissional do curso de Engelharia Florestal da Universidade Estadual de Roraima, Campus Rorainópolis.

As características observadas de cada indivíduo foram adaptadas de Andreatta et al. (2012) e Silva Filho et al. (2002). E classificados da seguinte forma:

a) Estado geral dos individuos avaliados:

1) Ótimo (indivíduo plenamente vigoroso e sadio, sem sinais de ataque de pragas, doenças ou injúrias mecânicas, mantendo suas características arquitetônicas);

2) Bom (indivíduo com boas condições gerais de vigor e sanidade, podendo apresentar algum sinal de deficiência superficial, ataque de pragas ou doenças, ou injúria mecânica superficial);

3) Regular (indivíduo em início de declínio, podendo apresentar ataque severo de pragas, doenças, ou injúrias mecânicas, descaracterizando sua arquitetura);

4) Péssimo (indivíduo em estado avançado e irreversível de declínio, com ataque ou dano intenso de pragas, doenças, deficiências, prejudicando a função do indivíduo na arborização e causando risco de queda ou morte do vegetal); e

5) Morto (indivíduo morto ou em estado de morte iminente, perdendo a função na arborização);

b) Copa:

1) Normal (quando a copa apresentava arquitetura característica da espécie);

2) Parcialmente deformada (copa um pouco diferente da normal e mostrando sinais leves de poda, contudo, não apresentando danos estruturais na sua arquitetura);

3) Deformada (quando a arquitetura estava diferente do padrão da espécie, assimétrica ou exibindo sinais de podas drásticas);

c) Desenvolvimento do sistema radicular das árvores em relação a calçada:

1) Presença de danos ao pavimento (quando o
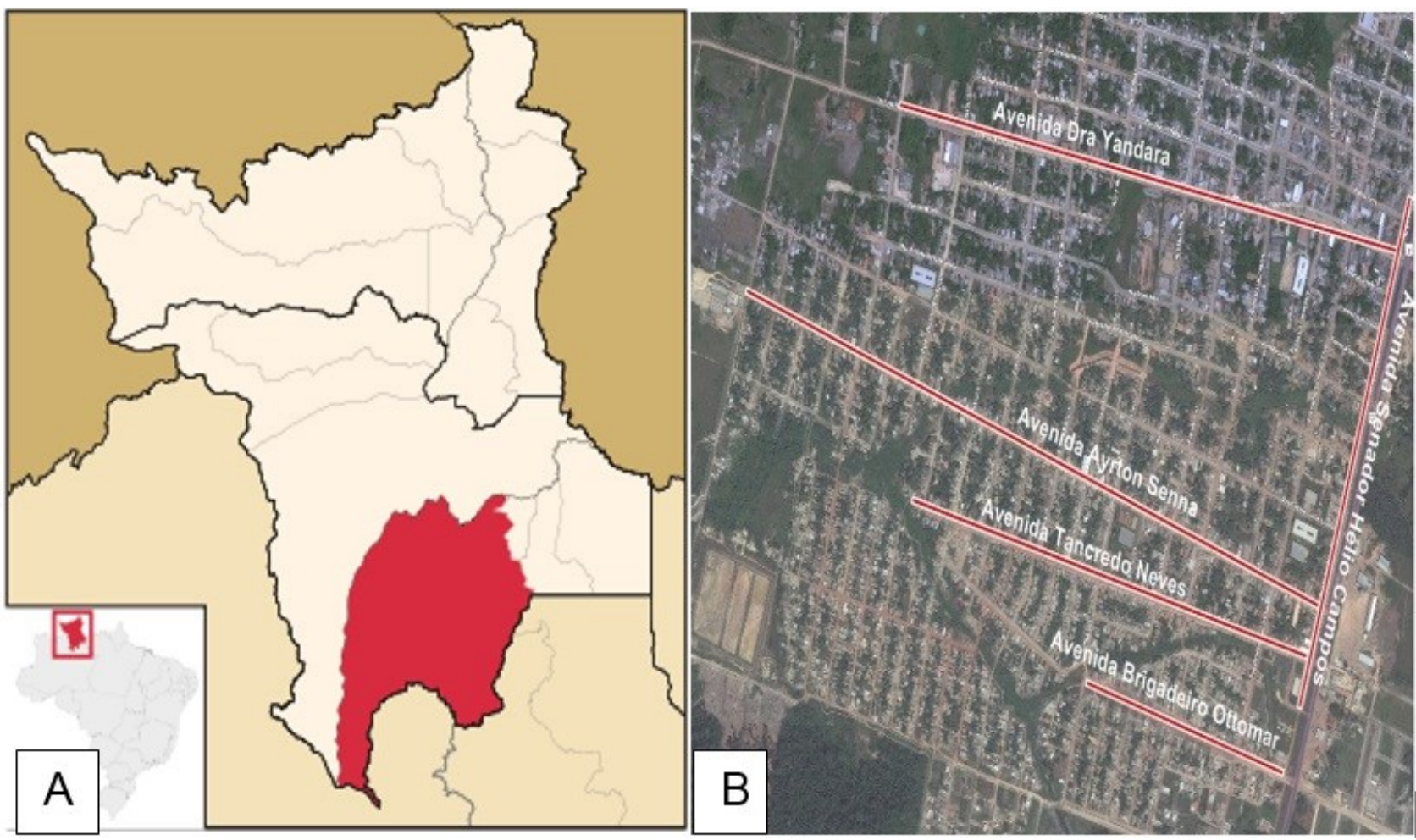

Figura 1. Localização da área de estudo. A: Mapa de Roraima com destaque para o Município de Rorainópolis. B: Avenidas do Município estudado. Adaptado de Bing Maps (2016). 
sistema radicular interfere na calçada);

2) Ausência de danos ao pavimento (quando o sistema radicular não interfere na calçada).

\section{RESULTADOS E DISCUSSÃO}

\section{INVENTÁRIO FLORÍSTICO}

As cinco avenidas inventariadas totalizaram 442 indivíduos, sendo que 48\% são plantas arbustivas e $52 \%$ plantas arbóreas, como pode ser observado na Tabela 1 e 2 . Observou-se que as espécies arbustivas estão distribuídas em cinco espécies e quatro famílias, sendo Ixora coccinea L. (60,09\%) a espécie mais frequente (Tabela 1).

De acordo com a Tabela 1, as espécies que obtiveram os menores valores de frequência relativa são Sansevieria trifasciata L. e Cereus fernambucensis L. Quanto às espécies arbóreas, pôde ser observado que estão arranjadas em 16 espécies e 12 famílias, sendo o Ficus benjamina L. a espécie que ocorre com maior frequência $(42,79 \%)$. As menores frequências ocorrem com as espécies: Tamarindus indica L. (0,44\%), Psidium sp. $(0,44 \%)$, Psidium guajava L. var. Ogawa III $(0,44 \%)$ e Rutaceae sp $(0,44 \%)$. (Tabela 2$)$.

\section{INVENTÁRIO FLORÍSTICO DAS AVENIDAS}

\section{Avenida Brigadeiro Ottomar de Souza Pinto}

O inventário florístico realizado demonstrou que as espécies dominantes são Pachira aquatica Aubl. (70,83\%) seguida da espécie Mangifera indica L.com (25\%). Observou-se que praticamente todas as espécies plantadas no canteiro central estavam com os seus troncos pintados de cal (Figura 2), exceto duas mudas de Mangifera indica no local (fase inicial de vida de uma planta).

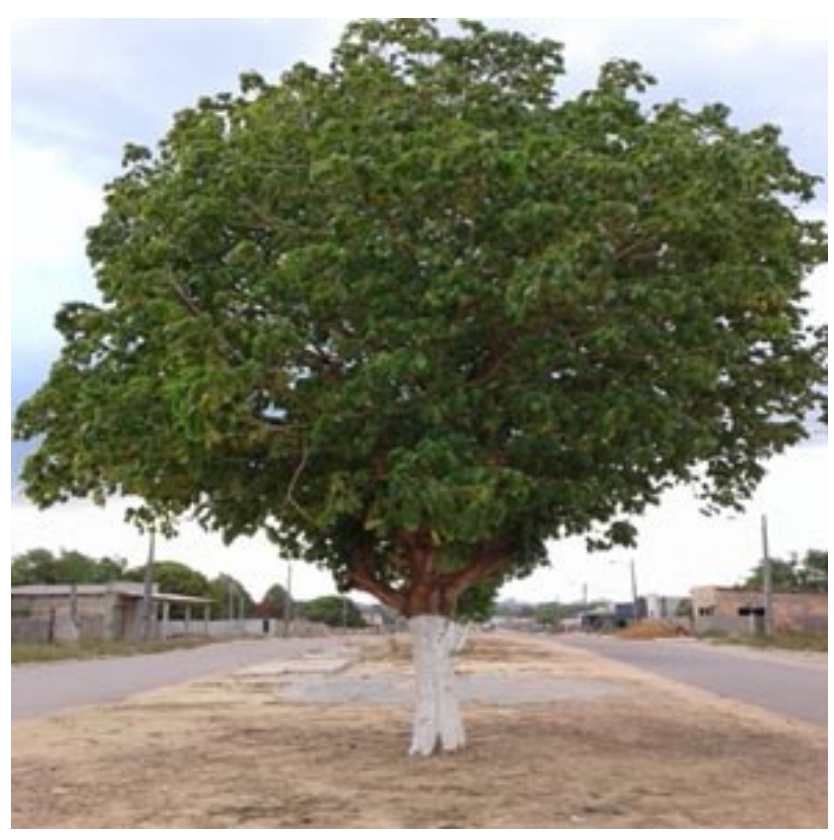

Figura 2. Pachira aquatica Aubl com cal recémaplicado na Avenida Brigadeiro Ottomar em Rorainópolis-RR, 2016.

Santos \& Teixeira (2001) afirmam que o cal esteriliza o tronco e evita o surgimento de organismos benéficos como os líquens que são ótimos indicadores de qualidade do ar.

Segundo Frigieri (2013), algumas espécies de árvores realizam trocas gasosas através de estruturas presentes nos caules. Dessa forma, pintá-los com cal pode

Tabela 1. Lista de espécies arbustivas do inventário florístico das principais Avenidas de RorainópolisRR, 2016

\begin{tabular}{llccc}
\hline NOME POPULAR & NOME CIENTIFICO & FAMILIA & ORIGEM & FR (\%) \\
Ixora & Ixora coccinea L. & Rubiaceae & Exótica & 60,09 \\
Pingo-de-ouro & Duranta erecta aurea L. & Verbenaceae & Nativa & 34,27 \\
Ixora amarela & Ixora sp. & Rubiaceae & Exótica & 4,69 \\
Espada-de-são-jorge & Sansevieria trifasciata L. & Asparagaceae & Exótica & 0,47 \\
Mandacaru-da-praia & Cereus fernambucensis L. & Cactaceae & Nativa & 0,47 \\
\hline
\end{tabular}


Tabela 2. Lista de espécies Arbóreas do inventário florístico das principais Avenidas de Rorainópolis-RR, 2016.

\begin{tabular}{llllc}
\hline NOME & NOME CIENTíFICO & FAMíLIA & ORIGEM & FR (\%) \\
Fícus & Ficus benjamina L. & Moraceae & Exótica & 42,79 \\
Fícus variegata & Ficus variegata L. & Moraceae & Exótica & 6,11 \\
Monguba & Pachira aquatica Aubl. & Malvaceae & Nativa & 9,17 \\
Oiti & Licania tormentosa (Benth.) Fritsch & Chrysobalanaceae & Nativa & 6,11 \\
Mangueira & Mangifera indica L. & Anacardiaceae & Exótica & 7,42 \\
Ingazeiro & Inga sp. & Leguminosae & Exótica & 0,87 \\
Tamarina & Tamarindus indica L. & Leguminosae & Exótica & 0,44 \\
Clitoria & Clitoria fairchildiana Howard. & Leguminosae & Nativa & 4,80 \\
Goiaba brava & Psidium sp. & Myrtaceae & Nativa & 0,44 \\
Palmeira & Roystonea Oleracea (Jacq.) O. F. & Arecaceae & Exótica & 6,99 \\
Imperial & Cook & & Exótica & 1,31 \\
Azeitoneira & Syzygium jambolanum (N. J. & Myrtaceae & Exótica & 0,87 \\
Coqueiro & Cocos nucfera L. & Arecaceae & Exótica & 10,48 \\
Palmeira-real & Archontophoenix cunninghamiana & Arecaceae & Nativa & 0,44 \\
Goiabeira & Psidium guajava L. & Myrtaceae & Nativa & 1,31 \\
Cajueiro & Anacardium occidentale L. & Anacardiaceae & Exótica & 0,44 \\
Limão- Tanjaa & Rutaceae sp. & Rutaceae & & \\
\hline
\end{tabular}

FR (\%): Frequência Relativa

impermeabilizar essas regiões e assim comprometer a saúde vegetal. Além disso, sob o ponto de vista econômico, tal prática implica em gasto desnecessário tanto em dinheiro quanto em tempo, pois tais recursos poderiam ser aproveitados de outras maneiras, por exemplo, adubando as árvores, realizando o controle de ervas daninhas, irrigando e realizando podas.

Nota-se que há uma deficiência no planejamento da arborização devido a existência de espécies frutíferas exóticas, uma vez que estas não são recomendadas para a arborização de vias públicas. De acordo com Santos \& Teixeira (2001), as espécies que produzem frutos grandes não são recomendadas para a arborização urbana, entre elas está incluída a Mangifera indica, pois esses frutos podem cair sobre a calçada, veículos e pedestres que circulam pelo local.

Ainda sobre o uso de espécies frutíferas na arborização de vias públicas Guizzo \& Jasper (2005), afirmam que as espécies com frutos grandes, além de causar sérios danos aos pedestres, podem danificar carros e outros objetos quando ocorre queda de frutos nos acessos públicos. Os autores ainda afirmam que nesses casos, a responsabilidade passa a ser do poder público por qualquer dano causado.

Ao utilizar espécies que produzam frutos grandes, normalmente consumidos pelas pessoas, em muitos casos será estimulada a depredação estrutural da planta pelo fato que pessoas podem arremessar pedras e paus para 
tentar derrubar os frutos (Motte \& Müller 2012).

\section{Avenida Doutora Yandara}

$\mathrm{Na}$ Avenida Doutora Yandara foi observado que a espécie que ocorreu com maior frequência foi a Ixora coccinea (46,83\%), seguida das espécies Ficus benjamina $(27,80 \%)$ e Roystonea Oleracea (Jacq.) O. F (7,32\%). A maior predominância de Ixora coccinea também foi observada por Santos et al. (2011) em estudo sobre a caracterização da arborização da orla do cais no Município de Altamira, PA. Em menor frequência estão as espécies Inga sp, Syzygium jambolanum e Cereus fernambucensis (0,45\%).

Nesta Avenida foram encontradas algumas árvores com injurias mecânicas e com ataque de praga, como é o caso de alguns indivíduos de Ficus benjamina e Syzygium jambolanum (Figura 3 e 4).

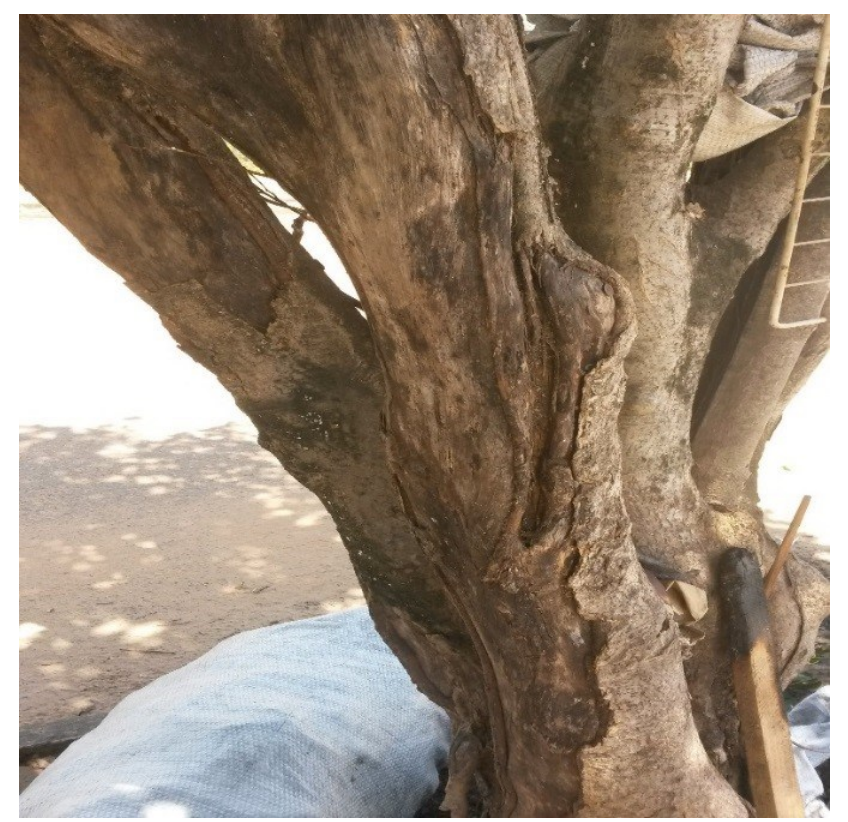

Figura 3. Ficus benjamina com injurias mecânicas na Avenida Dra Yandara em Rorainópolis-RR, 2016.

Essas injúrias provavelmente são causadas por vândalos que transitam por esses locais. Por sua vez as pragas encontradas encontrados em Syzygium jambolanum (N. J. Jacquin) O. F. Cook são chamadas de "erva-depassarinho", essa praga indica a necessidade de realização de cuidado e reparo na arborização desta Avenida, uma vez que a erva-depassarinho pode se dispersar para outras espécies não parasitadas.

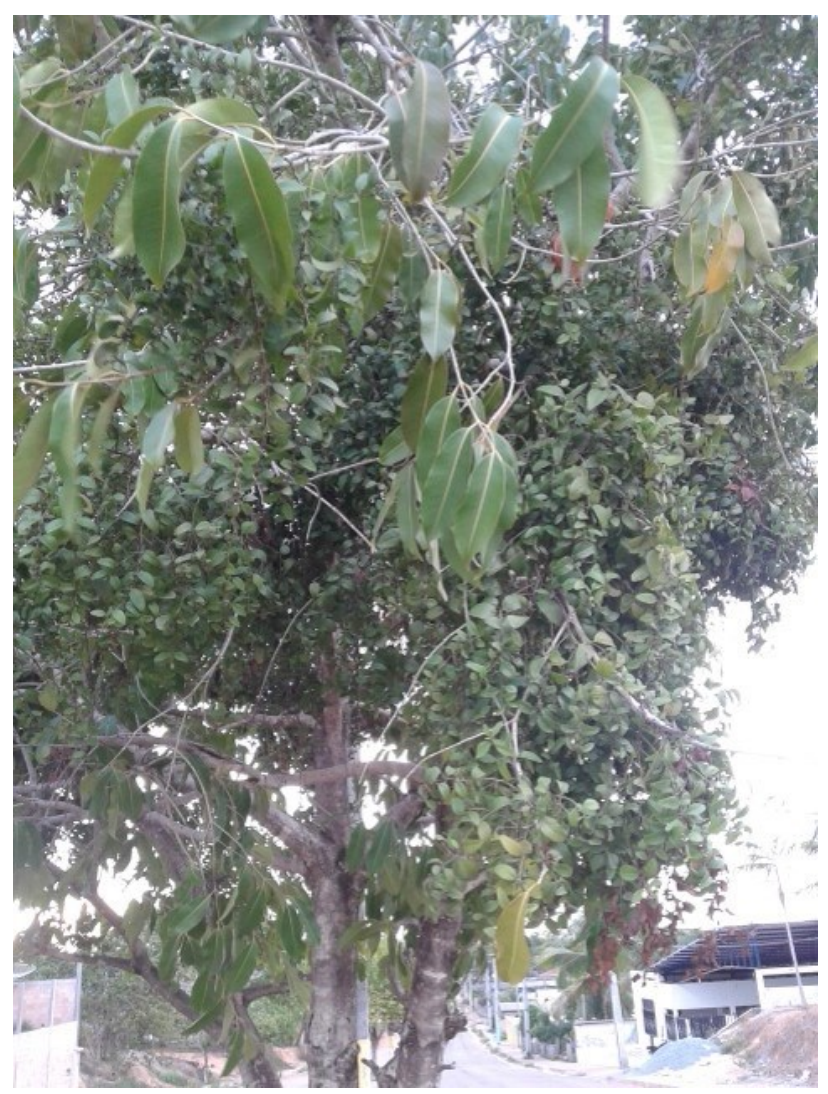

Figura 4. Syzygium jambolanum infestada por ervade-passarinho na Avenida Dra Yandara em Rorainópolis-RR, 2016.

\section{Avenida Senador Hélio Campos}

Na Avenida Senador Hélio Campos, as espécies que ocorreram com maior abundância foram Duranta erecta L., Ficus benjamina e Ixora coccinea com valores de frequência de $32.95 \%, 19,65 \%$ e $18,50 \%$, respectivamente. Com os menores valores de frequência destacam as espécies Syzygium jambolanum $(1,16 \%)$ e Rutaceae sp. $(0,58 \%)$.

$\mathrm{Na}$ presente via foi encontrado um espécime de Ficus benjamina inclinado por cima do canteiro central interrompendo o fluxo de transeuntes nesse ponto, fazendo com que as pessoas desçam da calçada para contornar a árvore inclinada (Figura 05).

A presente árvore deveria ser retirada e no lugar ser plantada outra espécie, para que este eventual transtorno seja sanado, facilitando desta forma o fluxo de pessoas. Tal sugestão é defendida por Stringheta (2005), o mesmo diz que as árvores enriquecem a paisagem, porém muitas dessas árvores trazem problemas para as áreas públicas e privadas da cidade e para que tais problemas sejam solucionados é necessário a supressão da árvore. 
Também foram encontradas três mudas de árvores plantadas juntas, sendo uma de Mangifera indica, uma de Anacardium occidentale L. var. e outra de Cocos nucifera L. Essas mudas provavelmente foram plantadas por moradores que vivem aos arredores da avenida para que posteriormente as mesmas possam ser plantadas em algum trecho desta via. Isso confirma o que é dito por alguns estudiosos como, Andreatta et al. (2011) e Silva Filho et al. (2002), em que alguns moradores fazem do espaço urbano a extensão dos seus quintas. Podemos dizer isso pelo fato que, das três mudas plantadas todas são espécies frutíferas que não são indicadas para a arborização em vias públicas.

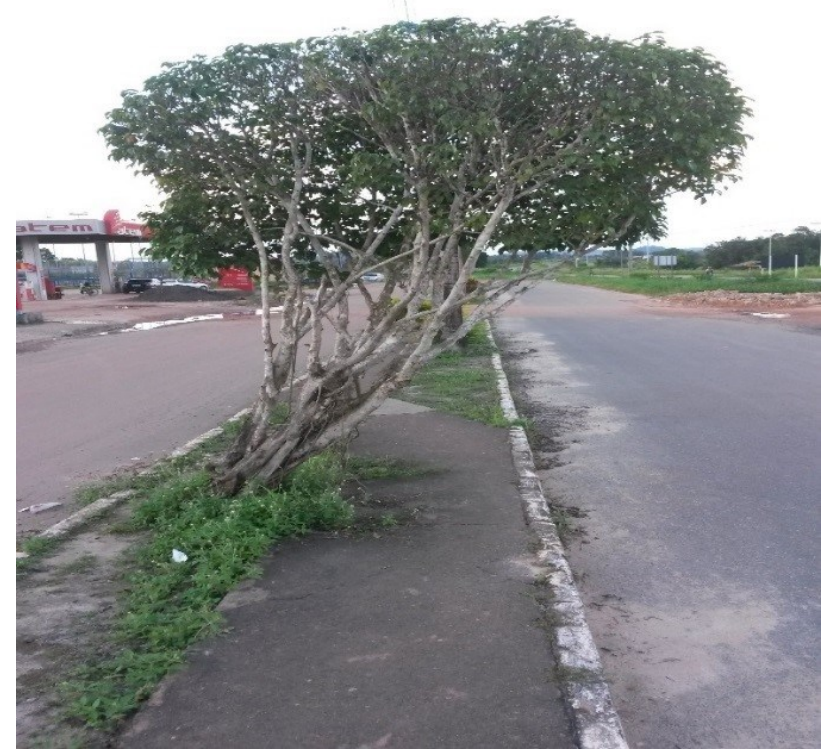

Figura 5. Ficus benjamina impedindo o fluxo dos transeuntes na Avenida Ayrton Senna em Rorainópolis-RR, 2016.

Alguns problemas que foram encontrados na Avenida Doutora Yandara, também ocorreram na Avenida Senador Hélio Campos, como por exemplo, mudas de árvores próximas das outras, presença de formigueiros na base do tronco de um espécime de Ficus benjamina e um espécime de Syzygium jambolanum com ataque de erva-de-passarinho. O ideal é que seja feita a manutenção correta dessas árvores, como por exemplo, desbastar uma das árvores que está competido com a outra, eliminar o formigueiro da base do tronco do Ficus benjamina e retirar a erva- de-passarinho do pé de Syzygium jambolanum para que o mesmo não venha morrer por causa desta praga.

Seitz (1996) afirma que as árvores necessitam de cuidados, com podas de manutenção ou limpeza, que visam evitar problemas futuros com galhos secos que possam cair, e a eliminação de focos de fungos e plantas parasitas, que enfraquecem os galhos.

Ainda neste contexto, Copel (2009) define que a manutenção de árvores no meio urbano compreende todas as práticas necessárias para manter as árvores com saúde, vigor e sempre compatíveis com o ambiente urbano. Além disso, o mesmo afirma que as atividades de manutenção mais comumente necessárias são a irrigação, a adubação complementar, tratos preventivos ou curativos de pragas e doenças, podas e as substituições de indivíduos ou de espécies.

As árvores em vias públicas sem a devida manutenção podem apresentar riscos de queda e/ou infestação de pragas, podendo causar inúmeros acidentes físicos e materiais, além de danos à saúde pública (Bobrowski 2011).

$\mathrm{Na}$ Avenida Senador Hélio Campos foi constatado que esta possuiu uma boa distribuição de árvores, porém, existe uma grande deficiência no que diz respeito ao planejamento da arborização, pelo fato da ocorrência de grande quantidade de árvores exóticas e de espécies frutíferas. Salienta-se que do total de todas as árvores encontras na Avenida (90,75\%) são exóticas, quesito este que não é defendido pelo manual de arborização urbana do estado de Minas Gerais (2011).

\section{Avenida Ayrton Sena}

Nesta Avenida observou-se que as espécies que ocorreram com maior predominância foram as espécies Ficus variegata $\mathrm{L}$. var. variegata $(31,43 \%)$, Clitoria fairchildiana Howard. (22,83\%) e Ficus benjamina (20\%). Esse resultado também foi semelhante ao que Moura \& Santos (2009) encontraram em seu estudo, em que ocorreu a maior predominância da espécie do gênero ficus nas vias dos bairros centro e centro norte na cidade de Várzea Grande no Estado de Mato Grosso.

Com valores inferiores destacam as espécies Licania tormentosa(Benth.) Fritsch, Pachira aquatica, Mangifera indica, Inga sp, Tamarindus indica e Sansevieria trifasciata todos com valores de frequência relativa de $2,86 \%$. 


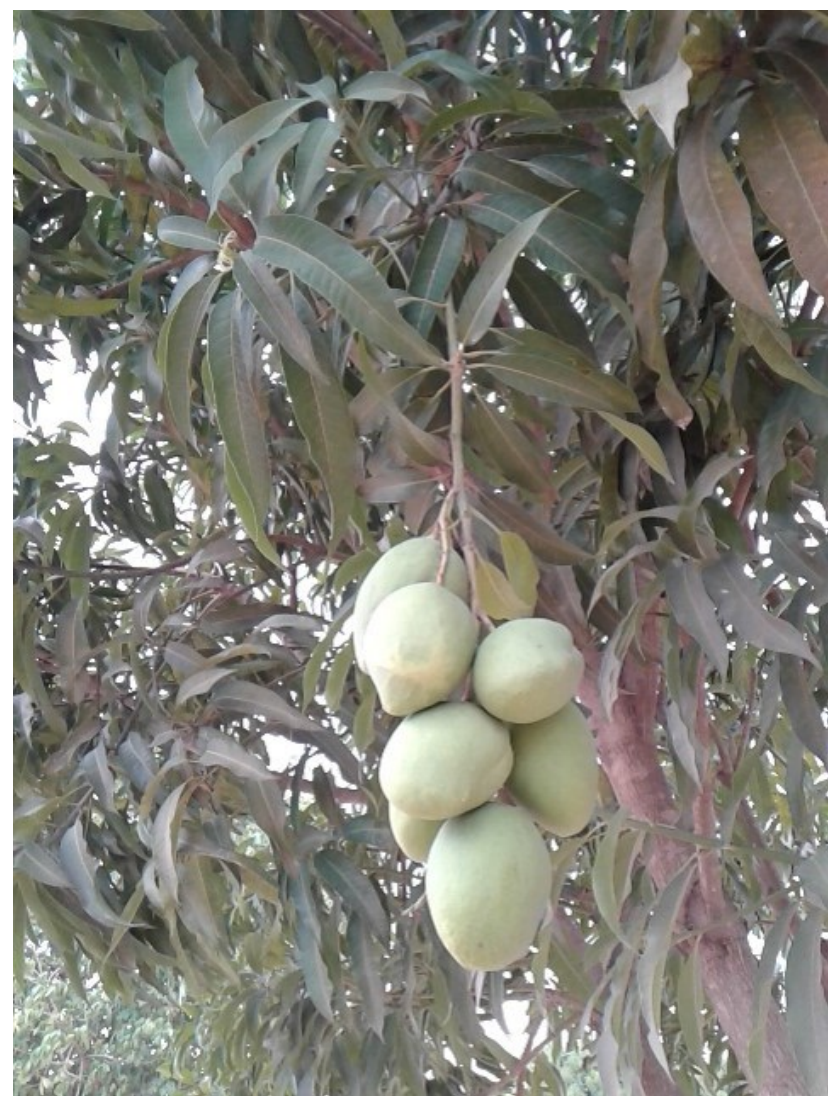

Figura 6. Mangifera indica com seus frutos na Avenida Ayrton Senna em Rorainópolis-RR, 2016.

Foram visualizados alguns problemas ao longo da Avenida como, por exemplo, a presença de árvores frutíferas, entre elas podemos citar Mangifera indica que já estava produzindo frutos (Figura 6), Licania tormentosa que apresentava necessidade de poda, pois a copa da mesma estava impedindo o fluxo dos transeuntes.

Ainda sobre a problemática encontrada na Avenida Ayrton Senna, podemos destacar outros dois encontrados como é o caso de um espécime de Ficus variegata que estava servindo como "lixeiro". Isso deve ter ocorrido devido ao fato de que alguns pedestres que quando passavam por aquele local penduravam lixo sobre os galhos da árvore.

Foi encontrada também uma espécie de Inga sp. que estava pondo em risco integridade dos transeuntes, pelo fato que a espécime estava com seus galhos deformados e ameaçando cair (Figura 7).

Deve-se então dessa forma realizar a remoção desse espécime para evitar qualquer tipo de transtorno aos pedestres. Diversos motivos são apresentados para a supressão de árvores, sendo que os inteiramente justificáveis

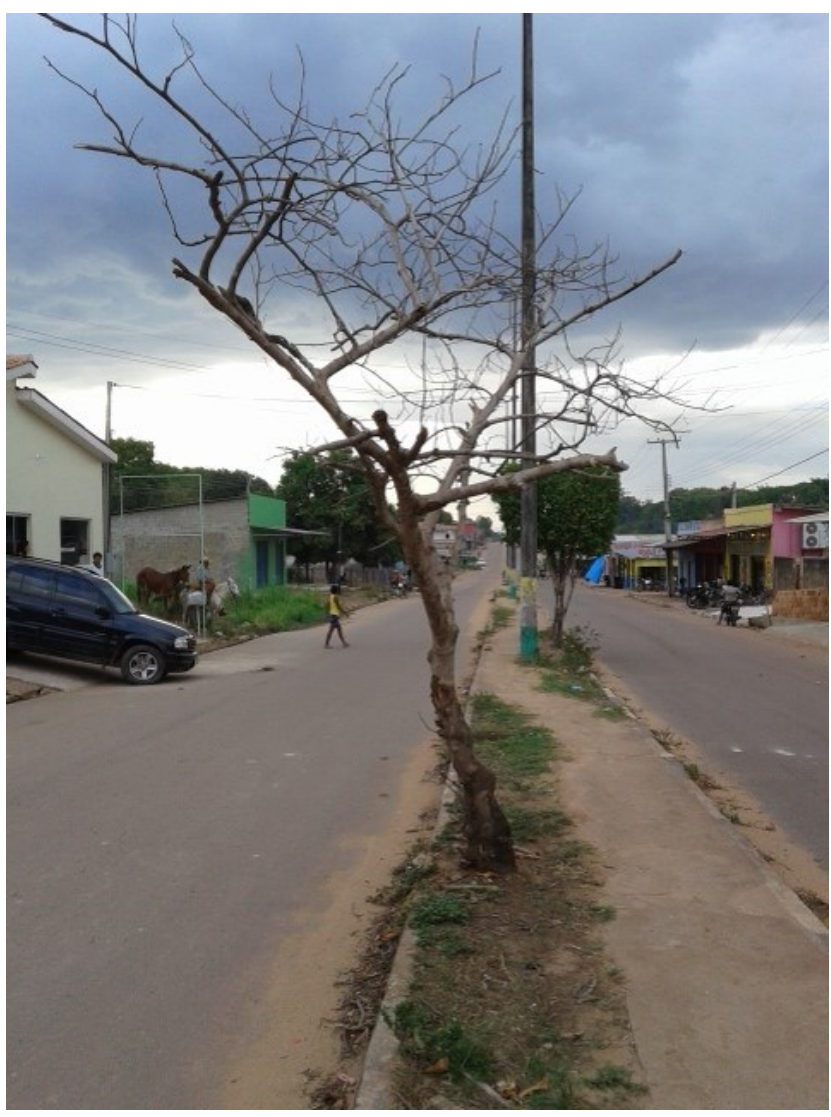

Figura 7. Inga sp. com galhos em risco de queda na Avenida Ayrton Senna em Rorainópolis-RR, 2016.

são os que colocam em risco a integridade da população (Gonçalves et al 2007).

Copel (2009), afirma que as árvores consideradas de risco devem ser removidas e substituídas por mudas da mesma espécie ou de outra espécie adaptada ao local e à região. Deve -se planejar novamente e verificar a possibilidade de mudança de local do plantio, bem como o porte da árvore a ser escolhida.

A respeito da análise da Avenida Ayrton Senna pode-se afirmar que esta Avenida está pouco arborizada, pelo fato que foram encontradas poucas árvores ao longo desta via. Essa é uma das vias mais movimentadas da cidade. Esta Avenida deveria ter um melhor planejamento na sua arborização para que os transeuntes que passam por esta via possam usufruir de uma forma mais satisfatória dos benefícios da arborização urbana.

\section{Avenida Tancredo Neves}

Foi observado que no canteiro central da Avenida não existe a presença de nenhuma espécie botânica lenhosa. Isso mostra a falta de interesse e planejamento por parte do poder 
público em beneficiar os transeuntes daquela Avenida.

Como já foi mencionada, a arborização das ruas garante vários benefícios tanto para os transeuntes, pessoas que moram ao longo das vias públicas e para a população da cidade no contexto geral. Vale ressaltar que a vegetação possui um papel importante como elemento estruturante e de percepção da paisagem (Pereira 2006).

È possivel observar que o canteiro central da presente Avenida é todo impermeável, impedindo qualquer possibilidade de ser realizada a arborização na mesma, seja por parte de moradores ou por profissionais capacitados. Seria necessário refazer o canteiro central para que a mesma seja arborizada para que os transeuntes e os moradores possam aproveitar de tais benefícios.

\section{ORIGEM DAS ESPÉCIES}

Observou-se que as espécies exóticas são as que mais predominam na arborização nas cinco Avenidas analisadas, das 21 espécies encontradas $61,90 \%$ são exóticas.

A respeito das nativas foram encontras

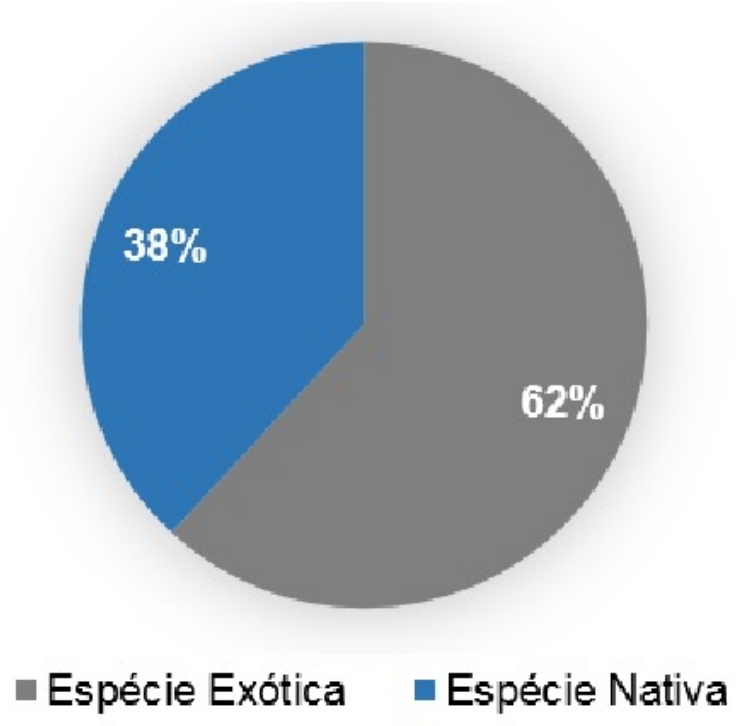

Figura 8. Origem das espécies vegetais de cinco avenidas de Rorainópolis, Roraima.

somente 08 , representando 38,10\% (Figura 08). Geralmente as espécies que predominam a arborização urbana são as exóticas. Esta colocação é confirmada por alguns autores como Silva (2009), o qual afirma que a composição da arborização urbana é com espécies exóticas. $\mathrm{O}$ autor também afirma que essas espécies ocasionam problemas, como por exemplo, invasão biológica, uma vez que ocupa o lugar de espécies nativas, por apresentarem desenvolvimento mais agressivo.

Mondin (2006) relata sobre o uso exagerado de espécies exóticas plantadas em jardins, praças e outras áreas públicas. Para ele é necessário às instituições governamentais desenvolverem mais pesquisas na área de plantas ornamentais, frutíferas e florestais nativas, tornando disponíveis para o mercado, a fim de diminuir a demanda por espécies exóticas.

A prioridade da utilização de espécies exóticas na arborização urbana pode ser devido a vários fatores, Andreatta et al. (2011), afirma que esta prioridade pode ser atribuída ao reflexo de tendências paisagísticas anteriores, pois quando levado ao ponto de vista estético é muito mais fácil encontrar espécies de grande beleza já selecionadas pelo homem.

\section{ESTADO GERAL DOS INDIVÍDUOS}

Das árvores estudadas nas cinco Avenidas apenas 52,26\% estão ranqueadas com o estado ótimo, ou seja, são indivíduos plenamente vigoroso e sadio, sem sinais de ataque de pragas doenças ou injúrias mecânicas mantendo suas características arquitetônicas. $42,99 \%$ dos indivíduos foram avaliados como bons, sendo assim indivíduos com boas condições gerais de vigor e sanidade apresentando desta formal algum sinal de deficiência superficial, ataque de pragas, doenças ou injúria mecânica superficial. No quesito regular foram apenas $1,58 \%$ dos indivíduos que se enquadraram, para melhor esclarecimento os indivíduos enquadrados na condição regular foram aqueles que estavam em início de declínio, podendo apresentar ataque severo de pragas, doenças, ou injúrias mecânicas, descaracterizando desta forma sua arquitetura. $\mathrm{Na}$ condição de péssimo foram enquadrados somente $0,45 \%$ dos indivíduos, vale ressaltar que estes estavam em estado avançado e irreversível de declínio prejudicando desta forma a função do indivíduo na arborização e causando risco de queda ou morte do vegetal. Os demais $(2,71 \%)$ dos indivíduos se enquadraram na condição de morto perdendo desta forma a sua função na arborização como podemos observar na Figura 9. 


\section{$52,26 \%$}

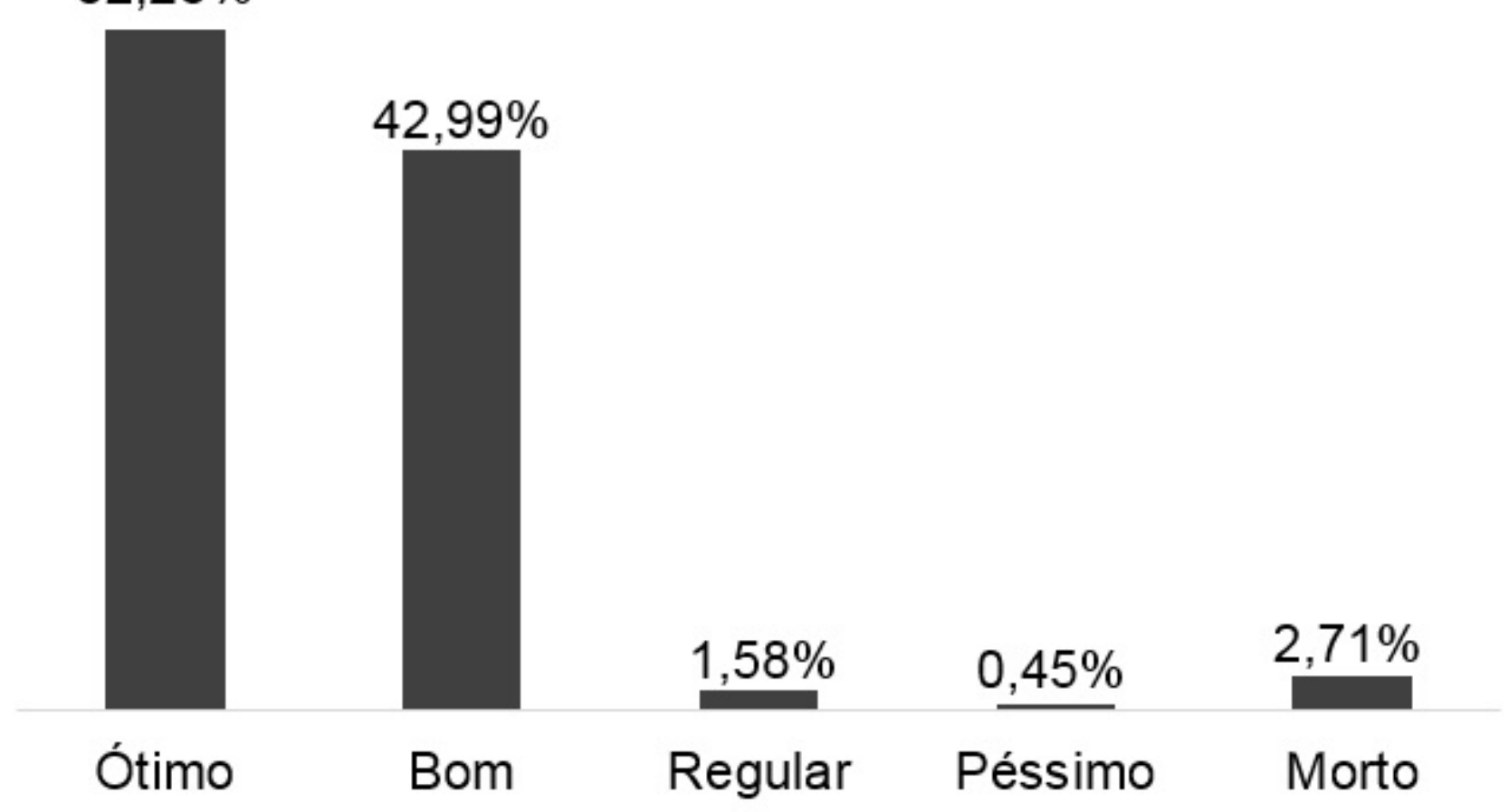

Figura 9. Estado geral das espécies vegetais das avenidas estudadas em Rorainópolis-RR.

\section{INTEGRIDADE DA COPA}

Foi observado que $23,02 \%$ dos indivíduos possuíam suas copas normais, ou seja, suas copas apresentaram arquitetura característica da espécie, pelo fato de não terem sido submetidas a nem um tipo de poda.

Já nas condições de copas parcialmente deformada foram cerca de $74,65 \%$ de indivíduos que apresentaram deformação em sua copa. Vale ressaltar que as copas estavam um pouco diferente da normal, mostrando sinais leves de poda, contudo, não apresentam danos estruturais na sua arquitetura.

O motivo de essas espécies estarem com a grande quantidade de copas parcialmente deformadas é devido as mesmas estarem inseridas no canteiro central das vias públicas. Isso exige sua adequação ao meio para não ocasionarem transtornos às pessoas que transitam pelos canteiros centrais.

Segundo Milano \& Dalcin (2000), para que as árvores cumpram com suas funções no ambiente urbano, mantendo-se em estado adequado, é necessária a adoção de práticas sistematizadas de manutenção, dentre as quais os mesmos dizem que a poda deve ser conduzida por profissionais e norteada por conhecimentos técnico-científicos.

Observou-se que 2,33\% das plantas apareceram com as copas deformadas, sendo que arquitetura dessas espécies estava diferente do padrão, exibindo sinais de podas drásticas. A Figura 10 mostra a integridade da copa das árvores analisadas.

\section{DESENVOLVIMENTO DO SISTEMA RADICULAR}

Quanto ao desenvolvimento do sistema radicular dos indivíduos em relação à calçada observou-se que cerca de $1 \%$ apresentaram danos ao pavimento, ou melhor, danos as calçadas. Enquanto 99\% dos indivíduos amostrados não apresentaram danos ao pavimento, ou seja, o sistema radicular dessas árvores não interfere na calçada do canteiro central das Avenidas estudadas.

\section{CONSIDERAÇÕES FINAIS}

Existe uma homogeneidade entre as espécies que ocorrem nas vias analisadas. Fator este que não é prejudicial à arborização das cinco Avenidas, pelo fato que esta homogeneidade contribui para a repetição dos tratos culturais das espécies das vias estudadas. 


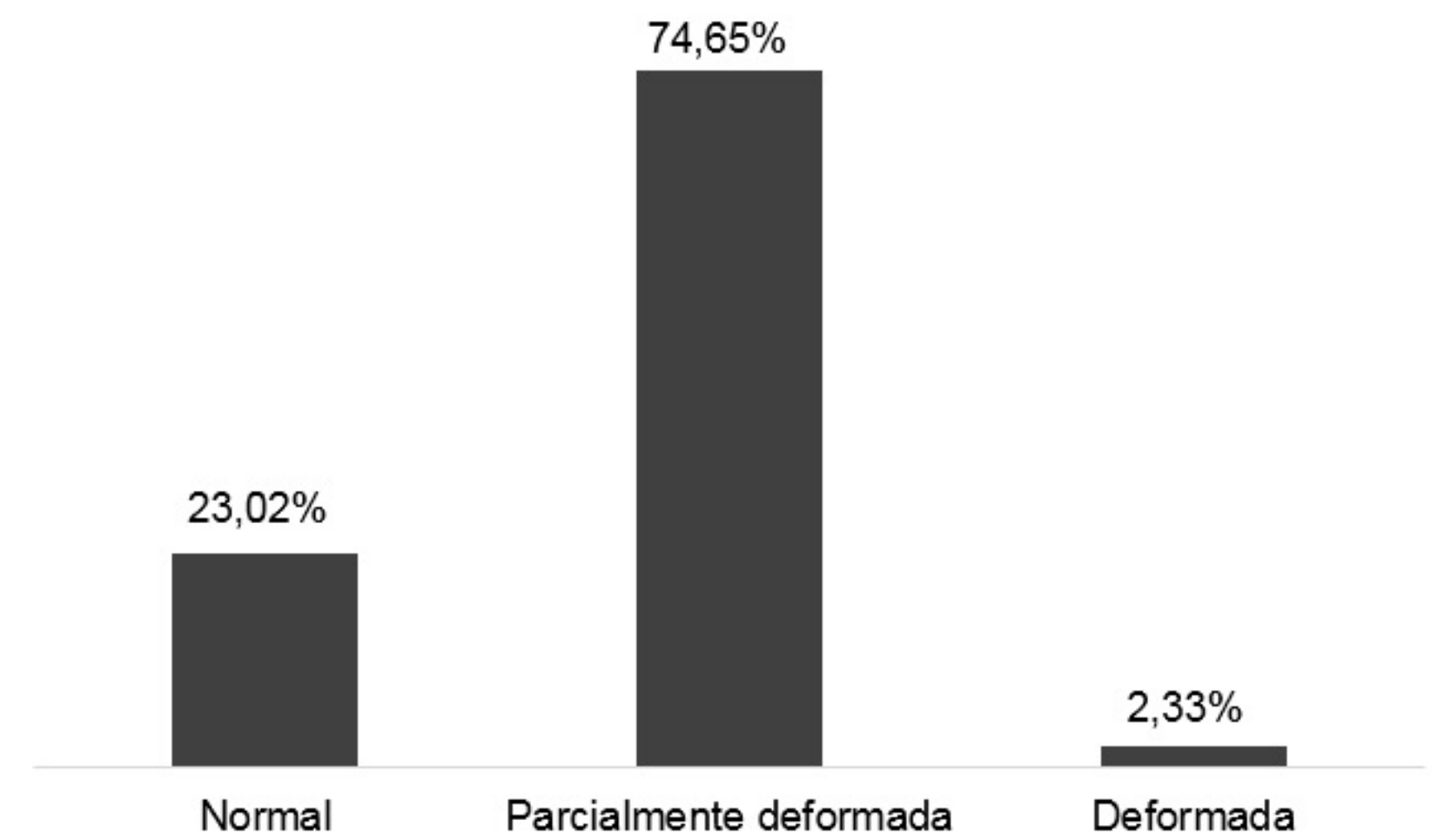

Figura 10. Integridade da copa das espécies vegetais das principais avenidas estudadas em RorainópolisRoraima.

Há uma grande ocorrência de espécies arbustivas nas vias analisadas, isto diminui alguns benefícios ofertados pela arborização como, por exemplo, área de sombreamento e ocasiona a diminuição do conforto térmico.

Observou-se que existe uma maior frequência de espécies exóticas, cerca de $(62 \%)$. Recomenda-se o plantio de espécies nativas do bioma local, para que se torne possível a introdução das mesmas na arborização urbana do presente Município, valorizando desta forma as espécies típicas deste bioma, conservando algumas espécies que por ventura possam a vir entrar na lista de extinção.

Em relação à fitossanidade das árvores analisadas houve superioridade dos indivíduos em ótimas condições. Quanto ao estado geral da copa, a maioria dos indivíduos apresentaram suas copas parcialmente deformadas, ou seja, sobre $\mathrm{o}$ efeito de poda. A respeito do desenvolvimento do sistema radicular cerca de 99\% dos indivíduos não apresentaram danos as calçadas das Avenidas inventariadas.

Quanto ao quantitativo de espécies pode -se observar que as espécies que ocorreram com maior predominância nas vias estudadas foram, Ixora coccinea, Ficus benjamina e Duranta erecta aurea com frequência de $(28,96 \%), \quad(22,17 \%), \quad(16,52 \%)$ respectivamente. Logo, a realização de novas pesquisas que evidenciem a eficácia do Clube de Ciências na escola e a utilização de novos métodos avaliativos que meçam a aprendizagem de forma qualitativa $\mathrm{e}$ significativa, contribuirá para que novas ferramentas avaliativas sejam implantadas na escola.

\section{REFERÊNCIAS BIBLIOGRÁFICAS}

Andreatta, T. R. et al. 2011. Análise da arborização no contexto urbano de Avenidas de Santa Maria, RS. Revista da Sociedade Brasileira de Arborização Urbana 6(1):36-50, mar 2011.

Bobrowski, R. 2011. Estrutura e dinâmica da Arborização de Ruas de Curitiba, Paraná, no periodo 1984-2010. 144f. Dissertação (Mestrado Em Engenharia Florestal) Setor De Ciências Agrárias, Universidade Federal Do Paraná, Curitiba.

Frigieri, F. F. 2013. Pintar o tronco das árvores com cal faz bem. Disponível em. < https:// plantandovida.wordpress.com/2013/02/06/ pintar-o-tronco-das-arvores-com-cal-faz-bem/ >. Acesso em: 12 fev. 2016.

CEMIG (Companhia Energética De Minas Gerais). 2011. Manual de arborização. Belo Horizonte: Fundação Biodiversitas, Disponível em: < http://www.cemig.com.br/sites/imprensa/pt-br/ Documents/ Manual_Arborizacao_Cemig_Biodiversitas.pdf >. Acesso em: 19 jan. 2016. 
FGV (Fundação Getúlio Vargas). 2004. Plano de Desenvolvimento Local Integrado e Sustentável - PDLIS - Município de Rorainópolis. Programa Calha Norte - PCN.

Gonçalves W., Stringheta, A. C. O.\& Coelho, L. P. 2007. Análise de Árvores Urbanas para fins de supressão. Revista da Sociedade Brasileira de Arborização Urbana 2 (4): 1-19

Guizzo, D. J. \& Jasper, A. 2005. Levantamento das espécies arbóreas dos passeios das vias públicas do Bairro Americano de Lajeado - RS, com indicação de problemas já existentes. Pesquisas Botânica 56: 185- 208.

IBGE (Instituto Brasileiro De Geografia E Estatísticas).Cidades@. Disponível em. < http http://cidades.ibge.gov.br/xtras/perfil.php? codmun=140047> $>$. Acesso em: 12 fev. 2016.

Lorenzi, H. 1992. Árvores brasileiras: manual de identificação e cultivo de plantas arbóreas nativas do Brasil. Nova Odessa: Instituto Plantarum. 352p.

Lorenzi, H. 2002. Árvores brasileiras: manual de identificação e cultivo de plantas arbóreas nativas do Brasil. Nova Odessa: Instituto Plantarum. 368p.

Lorenzi, H. et al. Árvores exóticas no Brasil: madeireiras, ornamentais e aromáticas. Nova Odessa: Instituto Plantarum, 2003. 368p.

Lorenzi, H \& Souza, H. M. 2008. Plantas ornamentais no Brasil: arbustivas, herbáceas e trepadeiras. Nova Odessa: Instituto Plantarum. $1088 \mathrm{p}$.

Milano, M. \& Dalcin, E. 2000. Arborização de vias públicas. Rio de Janeiro: Light. 206p.

Mondin, C. A. 2006. Espécies vegetais exóticas invasoras em florestas no Rio Grande do Sul. In: CONGRESSO NACIONAL DE BOTÂNICA. p. 529-531. Disponível em: < $\mathrm{http}: / /$ revistaseletronicas.pucrs.br/ojs/index.php/ fabio/article/viewFile/254/3005 >. Acesso em: 15 maio. 2016.

Motte, N. \& Müller, N. G. 2012. Diagnóstico da Arborização Urbana no Município de Tuparendi -RS. Revista da Sociedade Brasileira de Arborização Urbana 7(4): 27-36.

Moura, T. A. \& Santos, V. L. L. V. 2009. Levantamento Quali-Quantitativo de espécies Arbóreas e Arbustivas na Arborização viária Urbana dos Bairros Centro e Centro Norte, Várzea Grande, Mato Grosso, Brasil. Revista Brasileira de Arborização Urbana 1(1): 97-117.

Paranaense, C. Arborização de via públicas. Disponível em <http://www.copel.com/hpcopel/ guia_arb/a_arborizacao_urbana2.html $>$. Acesso em: 22 Jan.2016.
Pereira, R. I. 2006. O sentido da paisagem e a paisagem consentida: projetos participativos na produção do espaço livre público. Tese (Doutorado em Engenharia Florestal). Universidade de São Paulo. 2006. Disponível em: < http://www.teses.usp.br/teses/ disponiveis/16/16135/tde-12032010-114340/ptbr.php >. Acesso em: 21 jan. 2016.

MDA. 2010. Plano Territorial De Desenvolvimento Rural Sustentavel: Propostas De Politicas Públicas Para O Territorio Sul De Roraima. Rorainópolis/RR. p. 120.

Santos, N.R.Z. \& Teixeira, I. F. 2001. Arborização de vias públicas: ambiente $\mathrm{x}$ vegetação. Santa Cruz do Sul: Instituto Souza Cruz.

Seitz, R. A. 1996. A Poda de Árvores Urbanas: $1^{\circ}$ Curso em Treinamento sobre Poda em Espécies Arbóreas Florestais e de Arborização Urbana. Fundação de Pesquisas Florestais do Paraná/ Curitiba. Disponível em: < http://www.ipef.br/ publicacoes/curso_arborizacao_urbana/ cap07.pdf >. Acesso em: 16 maio. 2016.

SEPLAN (Secretaria de Planejamento e Desenvolvimento de Roraima). 2009. Anuário Roraima em Números. Boa Vista/RR, ed. 2009. Disponível em: < http://www.seplan.rr.gov.br/ site/?governoderoraima $=$ estatisticas $>$. Acesso em: 01 fev. 2016.

SEPLAN. 2010. Informações Socioeconômicas do Município de Rorainópolis - RR/ Elaboração: Divisão de Estudos e Pesquisas] $1^{\text {a }}$ Edição. Boa Vista: CGEES/SEPLAN - RR.70p. Disponível em: $\quad<$ http://www.seplan.rr.gov.br/upload/ estatisticas/?

action $=$ download $\&$ file $=$ L2ZvbGRlciBSb3JhaW 1hIDIwMTUgLSBwcmV0by5wZGY $=>$. Acesso em: 21 mar. 2016.

Silva Filho, D.F. et al. 2002. Banco de dados relacional para cadastro, avaliação e manejo da arborização em vias públicas. Revista Árvore 26 (5): 629-642. Disponível em: < www.scielo.br/ $\mathrm{pdf} / \mathrm{rarv} / \mathrm{v} 26 \mathrm{n} 5 / \mathrm{a} 14 \mathrm{v} 26 \mathrm{n} 5 . \mathrm{pdf}>$. Acesso em: 05 fev. 2016.

Silva Júnior, O. A. B. \& Mônico, M. O. M. 1994. Arborização em Harmonia com a Infraestrutura Urbana. In $1^{\text {a }}$ Semana de Meio Ambiente. Prefeitura Municipal de Guarulhos: Secretaria de Meio Ambiente. Disponível em: $<>$. Acesso em: 22 maio. 2016.

Silva, L. M. et al. 2008. Inventário da arborização em duas vias de Mariópolis/PR. Revista da Sociedade Brasileira de Arborização Urbana 3 (1): 36-53.

Silva, P. S. 2009. Controles Operacionais na Arborização Pública. 35f. Monografia 
(Especialista em Engenharia de Produção) Instituto a vez do Mestre, Universidade Candido Mendes, Rio de Janeiro. Disponível em: < http://www.avm.edu.br/docpdf/

monografias_publicadas/k211331.pdf $>$. Acesso em: 01 mar. 2016.

Silva, R. 2012. Caracterização e análise qualiquantitativa da arborização em praças da área central da cidade de Arapiraca, AL. Revista da Sociedade Brasileira de Arborização Urbana 7 (2):102-115.

Stringheta, A.C.O. 2005. Arborização Urbana no Brasil. Revista Ação Ambiental 33: 9-11. 